\title{
Simple prosthesis versus prosthesis plus titanium-coated polypropylene mesh for implant-based immediate breast reconstruction after total mastectomy for breast cancer
}

\author{
Xiaoli Yao ${ }^{1}$, Yueyue Guo ${ }^{1}$, Yi Tu${ }^{1}$, Feng Yao ${ }^{1}$, Chuang Chen ${ }^{1}$, Shengrong Sun ${ }^{1}$, Xinghua Zhang ${ }^{2}$ \\ ${ }^{1}$ Department of Breast and Thyroid Surgery, ${ }^{2}$ Department of Thoracic Surgery, Renmin Hospital of Wuhan University, Wuhan 430060, China \\ Contributions: (I) Conception and design: X Yao; (II) Administrative support: Y Tu; (III) Provision of study materials or patients: F Yao, C Chen, S \\ Sun; (IV) Collection and assembly of data: Y Guo; (V) Data analysis and interpretation: X Zhang; (VI) Manuscript writing: All authors; (VII) Final \\ approval of manuscript: All authors. \\ Correspondence to: Xiaoli Yao, MD. Department of Breast and Thyroid Surgery, Renmin Hospital of Wuhan University, Wuhan 430060, China. \\ Email: jie82jie@163.com.
}

Background: Our study compares the cosmetic effects, postoperative complications, and quality of life of immediate breast reconstruction with simple prosthesis or prosthesis plus titanium-coated polypropylene mesh (TCPM) after total mastectomy for breast cancer.

Methods: In total, 69 patients who underwent total mastectomy, sentinel lymph node biopsy, and immediate prosthetic breast reconstruction from January 2015 to December 2018 in our hospital were selected, and their cosmetic effects, complications, and quality of life after reconstruction were recorded immediately after surgery and 6 months after surgery.

Results: Of these 69 patients, 29 were in the simple prosthesis group and 40 in the prosthesis + TCPM group. The incidence of surgical complications was $17.2 \%$ in the simple prosthesis group (5/29; including 4 cases of capsular contracture and 1 case of infection) $15.0 \%$ in the prosthesis + TCPM group (6/40; 1 case of flap necrosis, 2 cases of poor wound healing, 2 cases of hematomas, and 1 case of inadequate blood supply to nipple). The complications were successfully managed after symptomatic treatment in both groups. No prosthesis loss was noted. The incidence of postoperative complications showed there to be no significant differences between these two groups $\left(\mathrm{P}=0.06, \chi^{2}=0.80\right)$. The satisfaction rate of patients on cosmetic effects was $95.0 \%(38 / 40)$ in the prosthesis + TCPM group, significantly higher than that in the simple prosthesis group $(75.90 \%, 22 / 29)\left(\mathrm{P}=0.05, \chi^{2}=3.87\right)$. The quality of life in the simple prosthesis group at 2 weeks and six months after the operation was significantly lower than that in the prosthesis + TCPM group. The incidence rate of arm pain and fatigue at 2 weeks after operation was significantly higher than that in the prosthesis + TCPM group $\left(\mathrm{P}=0.04, \chi^{2}=4.42\right)$. The satisfaction of family life and sexual interest 6 months after the operation was also significantly lower in the simple prosthesis group than in the prosthesis + TCPM group $\left(\mathrm{P}=0.03, \chi^{2}=4.95\right)$.

Conclusions: Breast reconstruction with prosthesis combined with TCPM does not increase surgical complications and has a good cosmetic effect and high patient satisfaction. Thus, it is a safe and reconstruction method.

Keywords: Immediate breast reconstruction; titanium-coated polypropylene mesh (TCPM); cosmetic effect; complications

Submitted Nov 23, 2019. Accepted for publication Dec 16, 2019.

doi: 10.21037 /gs.2019.12.17

View this article at: http://dx.doi.org/10.21037/gs.2019.12.17 


\section{Introduction}

The rapid development of multidisciplinary intervention approaches significantly increased the long-term survival rate for breast cancer patients. The pursuit of a high quality of life has become an essential and urgent need for surgical patients, and the feasibility of breast reconstruction has been an important indicator of successful treatment (1). Breast reconstruction after a mastectomy is remarkably associated with the improvements in patients' psychosocial functioning and physical image, and therefore it has become a critical procedure during breast cancer treatment (2). The most common method of breast reconstruction after total mastectomy is implant-based breast reconstruction (3-5), which is a safe and straightforward technique that does not require the prolonged surgery or the use of donor tissue $(6,7)$. The basic principle of implant coverage during the traditional breast reconstruction is the application of "muscle-covering implants"; that is, after the mastectomy, a "pocket" is created under the chest wall muscle, and the implants are placed in the pocket (2). Muscle coverage can be either "complete" (full coverage of the prosthesis with muscle) or "partial" (the pectoralis major muscle covers only the upper pole) (8-10), with an attempt to avoid the exposure or removal of the implants when flap necrosis occurs after the mastectomy. However, partial muscle coverage increases the risk of incision splitting, prosthesis exposure, and even reconstruction failure after implantation $(10,11)$. Although the "complete" muscle coverage of the implants lowers the risk of exposure, it requires extensive muscle dissection, and muscle spasm/contractions can lead to pain and unnatural breast deformities. Additionally, none of these two techniques can reshape the natural inframammary fold and the final reconstructed breast on the opposite side is flat and difficult to maintain symmetry with the naturally sagging breast $(12,13)$.

In 2005, Breuing and Warren used acellular dermal matrix (ADM) to support and cover the lower pole of pectoral major muscle during primary implantation during mastectomy to resolve the unnaturally symmetrical shape of the breast due to chest wall muscle limitations (14). While the implants were placed on the deep side of the pectoral muscle, biological or synthetic ADM was sutured to the inframammary fold and the lower boundary of the pectoralis major muscle to cover the lower pole of the implants $(12,15)$. The ADM not only provides support for the lower pole of the implant but also increases the size of the pocket, which enables the use of one-step implant-based reconstruction in some cases (e.g., thin flaps; or, implantation of more than $300 \mathrm{~mL}$ of prostheses) (16). However, the ADM is derived from human cadaver dermis, which is expensive and challenging to harvest $(17,18)$. In contrast, titanium-coated polypropylene mesh (TCPM) is a synthetic titaniumized polypropylene and is the only synthetic patch approved by the China FDA for breast reconstruction.

TCPM has been commonly used in Europe at present, but with limited experience of use in China. In this article, we retrospectively analyzed the data of 40 breast cancer patients who had received TCPM-based breast reconstruction since 2017, and the results were compared with 29 cases of muscle coverage method that had been applied before 2017.

\section{Methods}

\section{General data}

We retrospectively analyzed the data of 40 patients who had their breasts reconstructed with TCPM (the prosthesis + TCPM group) in the Department of Breast and Thyroid Surgery of Wuhan University People's Hospital since 2017 , and the results were compared with those of 29 cases of reconstruction with muscle coverage method before 2017 (the simple prosthesis group). The Medical Ethics Committee approved the study of our hospital. The inclusion criteria were as follows: (I) with pathologically confirmed breast cancer; (II) having received skinpreserving subcutaneous mastectomy; (III) undergoing implant-based breast reconstruction voluntarily; (IV) with negative sentinel lymph nodes and less than $5 \mathrm{~cm}$ tumor diameter, and no postoperative radiotherapy was required; (V) breast reconstruction performed at once after mastectomy. The exclusion criteria included: (I) with incomplete data and/or unwilling to be followed up; (II) with a history of obesity, smoking, diabetes, and connective tissue disease; (III) with positive sentinel lymph nodes; (IV) with mental illness; and (V) with inflammatory breast cancer and previous radiation therapy. All patients signed informed consent. The postoperative complications, cosmetic effects, and quality of life were analyzed and compared between these two groups.

Case report forms were used to record the complications, including secondary bleeding, wound infections, wound healing issues, hematomas, skin changes (such as erythema or rippling), skin necrosis, and capsular contractures. The types and incidence of such complications were analyzed in 
Table 1 Harris scale

\begin{tabular}{ll}
\hline Excellent & Treated breast identical to untreated breast \\
\hline Good & Treated breast slightly different than untreated \\
Fair & $\begin{array}{l}\text { Treated breast different from untreated but } \\
\text { not seriously distorted }\end{array}$ \\
Poor & Treated breast seriously distorted \\
\hline
\end{tabular}

both groups. The Harris scale (19) (Table 1) (1, poor; 2, fair; 3 , good; and 4 , excellent) was used to compare the cosmetic effects based on the standardized photos 6 months before and after surgery. The EORTC QLQ C30 and BR23 questionnaires were used to assess the impact of these two techniques on the quality of life.

The new TCPM (PRM Medical, Cologne, Germany) is made of non-absorbable titaniumized light-weight polypropylene with a monofilament structure.

\section{Surgical methods}

\section{Simple prosthesis group}

Patients underwent prosthetic breast reconstruction after skin-preserving subcutaneous mastectomy. The patients were asked to take a supine position. After successful anesthesia, a prosthetic pocket, which was found above the external oblique muscle, was created along the lateral and posterior margins of the pectoralis major muscle and the medial margin of the anterior serratus muscle. The head of the operating table was raised by $60^{\circ}$ during the operation. A dilator was placed in the subcutaneous pocket, and the amount of water injected into the dilator was adjusted. After the sizes and shape of bilateral breasts became close, the dilator was removed. According to the amount of water injected in the dilator, and the breast dimensions measured before surgery, the proper volume of the prosthesis was placed behind the pectoralis major muscle to complete the reconstruction. Two drainage tubes were placed: one was in the inframammary fold and the other at the outer edge of the pocket. The incision was sutured layer by layer. The drainage tubes were removed if the drainage volume was below $30 \mathrm{~mL} / \mathrm{d}$ for two consecutive days. Antibiotics were used before and after surgery. Strenuous exercise with upper limbs was restricted for two weeks after surgery.

\section{Prosthesis + TCPM group}

The submammary folds, as well as the outer and inner boundaries of the breast, were marked at a standing position before surgery. After the patient was successfully anesthetized, a radial incision in the upper quadrant of the breast was selected. The skin flap was mobilized, and a subcutaneous glandectomy was performed. The posterior pectoralis major space was mobilized between the pectoralis major muscle and pectoralis minor muscle: medial to the parasternal ligament of the breast, lateral to the anterior axillary line, superior to the 4th intercostal space, and inferior to the inframammary fold. The attachment point of the lower edge of the pectoralis major muscle was separated, and the attachment point of the medial edge was divided from the fourth rib. The TCPM was sutured to the stump below the pectoralis major muscle and the lateral margin to create a prosthetic pocket. The head of the operating table was raised by $60^{\circ}$ during the operation. A dilator was placed in the subcutaneous pocket, and the amount of water injected into the dilator was adjusted. After the sizes and shape of bilateral breasts became close, the dilator was removed. According to the amount of water injected in the dilator and the breast dimensions measured before surgery, the proper volume of the prosthesis and the TCPM with appropriate size were selected. The prosthesis was placed into the gap between the pectoralis major muscle and the TCPM. The mesh was folded to wrap the prosthesis completely. The position of the prosthesis was adjusted to make it symmetrical with the contralateral side. The lateral side of the mesh was sutured to the anterior serratus fascia. A decision of reconstruction (or not) of submammary folds was made during the surgery (20). Two drainage tubes were placed: one was in the inframammary fold and the other at the outer edge of the pocket. The drainage tubes were removed if the drainage volume was below $30 \mathrm{~mL} / \mathrm{d}$ for two consecutive days. Antibiotics were used before and after surgery. Strenuous exercise with upper limbs was restricted for two weeks after surgery.

\section{Statistical analysis}

Statistical analysis was performed using SPSS 23.0 software package. Comparisons of parameters were based on the $\chi^{2}$ test, $t$-test, or Fisher's exact test. A P value of $<0.05$ was considered statistically significant.

\section{Results}

\section{General data}

There were 40 patients in the Prosthesis + TCPM group 
Table 2 Basic information of two groups of patients undergoing immediate breast reconstruction

\begin{tabular}{|c|c|c|c|c|}
\hline Characteristic & $\begin{array}{c}\text { Prosthesis + TCPM } \\
\text { group }(n=40)\end{array}$ & $\begin{array}{l}\text { Simple prosthesis } \\
\text { group }(n=29)\end{array}$ & $\chi^{2}$ value & $P$ value \\
\hline Age & & & 0.22 & 0.64 \\
\hline$>35$ & 27 & 18 & & \\
\hline $24-28$ & 12 & 5 & & \\
\hline$\geq 28$ & 5 & 2 & & \\
\hline Surgical method & & & 1.55 & 0.21 \\
\hline Carcinoma in situ & 9 & 7 & & \\
\hline Carcinoma in situ with microinfiltration & 10 & 5 & & \\
\hline Invasive carcinoma & 21 & 17 & & \\
\hline Volume of prosthesis & & & 0.74 & 0.39 \\
\hline$\leq 250$ (medium TCPM) & 25 & 21 & & \\
\hline 255-390 (large TCPM) & 15 & 8 & & \\
\hline Incision & & & 0.26 & 0.61 \\
\hline
\end{tabular}

TCPM, titanium-coated polypropylene mesh; BMI, body mass index; NSM, nipple sparing mastectomy; SSM, skin sparing mastectomy.

and 29 patients in the simple prosthesis group. The general clinical data of these subjects are summarized in Table 2. The age distribution, body mass index (BMI), surgical method, pathological type, prosthesis volume, and incision choice was matched in these two groups.

\section{Postoperative complications}

The incidence of postoperative complications was $17.2 \%$ in the simple prosthesis group, and the 5 cases of complications included 1 case of infection and 4 cases of capsular contracture. The incidence of postoperative complications was $15.0 \%$ in the prosthesis + TCPM group, and the 5 cases of complications included 1 case of partial flap necrosis, 1 case of poor wound healing, 1 case of reduced blood flow to the nipple, 2 cases of hematoma, and 2 cases of poor incision healing. The incidence of postoperative complications showed no significant difference between these two groups $\left(\chi^{2}=0.78, \mathrm{P}=0.38\right)$ (Table 3). Wound healing was associated with the auxiliary periareolar incision, a technique that results in poor wound healing at the T-shaped junction.

We further analyzed the effects of patient age, BMI, biopsy technique, the volume of the prosthesis, surgical method, and type of incision on the incidence of complications. The results showed that the type of incision and the biopsy technique were closely related to the occurrence of complications. The incidence of complications was significantly higher in patients undergoing subcutaneous glandectomy via radial incision 
Table 3 Incidence of complications in two groups

\begin{tabular}{|c|c|c|c|c|c|c|c|c|c|c|}
\hline Group & $\begin{array}{l}\text { Reduced blood } \\
\text { flow to the nipple }\end{array}$ & Hematoma & $\begin{array}{c}\text { Flap } \\
\text { necrosis }\end{array}$ & Infection & $\begin{array}{l}\text { Poor wound } \\
\text { healing }\end{array}$ & $\begin{array}{c}\text { Capsular } \\
\text { contractures }\end{array}$ & $\begin{array}{c}\text { Removal of } \\
\text { prosthesis }\end{array}$ & $\begin{array}{l}\text { Incidence of } \\
\text { complications }\end{array}$ & $\chi^{2}$ & $P$ value \\
\hline $\begin{array}{l}\text { Simple prosthesis } \\
\text { group }\end{array}$ & 1 & 0 & 0 & 1 & 0 & 3 & 0 & $5 / 29$ & 0.06 & 0.80 \\
\hline $\begin{array}{l}\text { Prosthesis + TCPM } \\
\text { group }\end{array}$ & 1 & 2 & 1 & 0 & 2 & 0 & 0 & $6 / 40$ & & \\
\hline
\end{tabular}

Note: In the prosthesis + TCPM group, two patients had hematomas, among whom one suffered from skin flap necrosis, and the other had poor wound healing. TCPM, titanium-coated polypropylene mesh.

Table 4 Factors associated with complications

\begin{tabular}{|c|c|c|c|}
\hline Risk factor & Incidence of complications & $\chi^{2}$ value & $P$ value \\
\hline$\leq 35$ & $4 / 24$ & & \\
\hline$>35$ & $7 / 45$ & & \\
\hline BMI & & 0.05 & 0.82 \\
\hline$\geq 24$ & $3 / 24$ & & \\
\hline Biopsy technique & & 5.18 & 0.02 \\
\hline Mammotome system & $8 / 26$ & & \\
\hline Open biopsy & $3 / 43$ & & \\
\hline 255-390 (large TCPM) & $5 / 23$ & & \\
\hline Incision & & 5.53 & 0.02 \\
\hline Radial incision & $2 / 38$ & & \\
\hline $\begin{array}{l}\text { A periareolar incision with or without } \\
\text { radial incision }\end{array}$ & $9 / 31$ & & \\
\hline Surgical method & & 0.004 & 0.95 \\
\hline NSM & $9 / 60$ & & \\
\hline SSM & $2 / 9$ & & \\
\hline
\end{tabular}

BMI, body mass index; TCPM, titanium-coated polypropylene mesh; NSM, nipple sparing mastectomy; SSM, skin sparing mastectomy.

and auxiliary periareolar incision than in patients receiving subcutaneous glandectomy via a radial incision $\left(\chi^{2}=5.53\right.$, $\mathrm{P}=0.02)$; in addition, the use of high-vacuum negativepressure biopsy device (the Mammotome System) was associated with significantly higher incidence of complications $\left(\chi^{2}=5.18, \mathrm{P}=0.02\right)$. However, age, BMI, the volume of the prosthesis, nipple sparing mastectomy (NSM), and skin sparing mastectomy (SSM) were not correlated to the incidence of complications (Table 4).

\section{Postoperative quality of life}

There were significant differences in the EORTC QLQ C30 and BR23 questionnaire results between the two treatment groups at two-time points ( 2 weeks and 6 months after surgery). At 2 weeks after surgery, a significantly 
Table 5 Impact of different reconstruction methods on the quality of life in two groups

\begin{tabular}{|c|c|c|c|c|}
\hline Parameters of quality of life & Simple prosthesis group & Prosthesis + TCPM group & $\chi^{2}$ value & $P$ value \\
\hline Arm pain $[>1]$ & 9 & 7 & & \\
\hline Fatigue $[3,4]$ & 7 & 5 & & \\
\hline Six weeks after surgery & & & 4.95 & 0.03 \\
\hline Sexual interest [3-4] & 3 & 1 & & \\
\hline
\end{tabular}

Note: Comparison of the parameters of quality of life. The table shows the significant differences between two-time points (the first postoperative visit and 6 months after surgery). Each parameter in the questionnaire is scored on a scale of 0 to 4 (1, no impact; 4 greatest impact); for example, the impact on family life: 1, no effect. A chi-square test was applied. TCPM, titanium-coated polypropylene mesh.

Table 6 Cosmetic effect evaluated by Harris scale

\begin{tabular}{lcccc}
\hline Group & Poor & Fair & Good & Excellent \\
\hline Simple prosthesis group & 1 & 6 & 17 & 5 \\
Prosthesis + TCPM group & 0 & 2 & 17 & 21 \\
\hline
\end{tabular}

TCPM, titanium-coated polypropylene mesh.

higher proportion of patients in the simple prosthesis group had arm pain and fatigue $\left(\chi^{2}=4.42, \mathrm{P}=0.04\right)$. After six months, a significantly higher proportion of patients in the simple prosthesis group had their family life affected $\left(\chi^{2}=4.95, \mathrm{P}=0.03\right)($ Table 5$)$.

\section{Cosmetic effect}

We evaluated the cosmetic effect of the patients 6 months after the operation. Two independent surgeons or orthopedists evaluated each patient according to the Harris scale. The excellent + good rate was $95 \%(38 / 40)$ in the prosthesis + TCPM group, which was significantly superior to that $[75.90 \%(22 / 29)]$ in the simple prosthesis group $\left(\chi^{2}=3.87, \mathrm{P}=0.05\right)$ (Table 6).

\section{Discussion}

We compared the aesthetic results of prothesis + TCPM and simple prothesis implantation in breast reconstruction in our current study. Both surgical methods met the patients' cosmetic satisfaction. While most patients rated the cosmetic results as good or excellent, cosmetic satisfaction was significantly higher in the prosthesis + TCPM group (Figure 1). The incidence of postoperative complications showed no significant difference between these two groups. There was one case of flap necrosis in the prosthesis + TCPM group, which might be due to (I) the preoperative use of the Mammotome System for mass resection, biopsy, and compression bandage resulted in local blood flow disorder; (II) the $395 \mathrm{~mL}$ of prosthesis placed was slightly larger; and (III) development of hematoma 1 week after surgery. These factors worked together to cause flap necrosis. However, the scope of necrosis was not significant, and the lesion healed after debridement and suture (Figure 2). Poor incision healing in another case in the prosthesis + TCPM group was related to the $\mathrm{T}$-shaped periareolar incision and the postoperative hematoma, and the incision healed after debridement and suture (Figure 3). Another patient, the prosthesis + TCPM group, suffered from poor nipple blood flow, which was also associated with the periareolar incision (Figure 4). One patient in the single prosthesis group developed an infection, which was controlled after treatment (Figure 5). All four patients had undergone minimally invasive mass resection on the Mammotome System before surgery. Statistical analysis showed that both preoperative minimally invasive biopsy and the periareolar incision were correlated to the complications of reconstruction $\left(\chi^{2}=5.18\right.$, $\mathrm{P}=0.02)$. A preoperative core needle biopsy can reduce the 

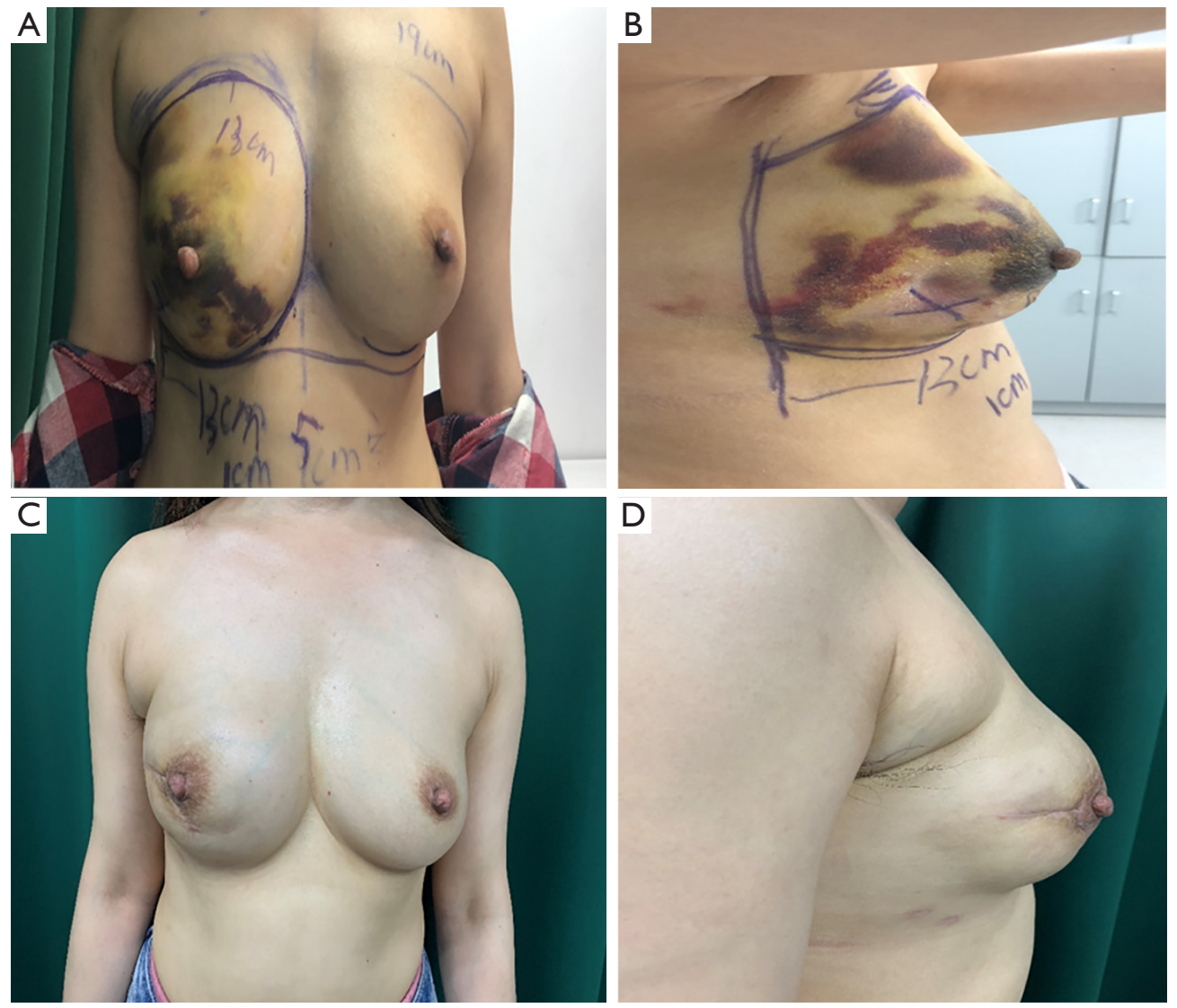

Figure 1 Good cosmetic effects after reconstruction in the prosthesis + TCPM group. (A,B) Frontal and lateral views of minimally invasive resection of the right breast at the 8 o'clock position after a diagnosis of carcinoma in situ were made; (C,D) frontal and lateral views of the breast 6 months after prosthesis + TCPM reconstruction. TCPM, titanium-coated polypropylene mesh.

complications of reconstruction surgery. The incidence of capsular contractures was high in the simple prosthesis group (Figure 6), which may be due to the small pocket. Therefore, the application of TCPM can release the lower edge of the pectoralis major muscle by expanding the cavity, which can re-shape the natural inframammary folds and meanwhile lower the incidence of capsular contractures.

Our current study also showed that compared with the simple radial incision in the outer upper quadrant, the use of radial incision in the outer upper quadrant plus periareolar incision was associated with significantly higher incidence of complications $\left(\chi^{2}=5.53, \mathrm{P}=0.02\right)$; in particular, there is a risk of poor healing at the T-shaped junction between the periareolar incision and the radial incision.

Its small sample size limited our study; however, unlike many other studies, we did not find any association between age or BMI and increased incidence of complications.

Rating of the quality of life showed that the simple prosthesis group had significantly poor outcomes (higher incidence of arm pain, $\mathrm{P}=0.04$; lower sexual desire, $\mathrm{P}=0.03$ ).

However, in this preliminary study, we demonstrated the value of TCPM in the immediate implant-based breast reconstruction in terms of the risk of reconstruction failure, the cosmetic effects assessed by medical professionals, and the quality of life of patients; no additional risk was identified.

Although there is no consensus on the ideal method for breast reconstruction with the prosthesis, breast reconstruction with the prosthesis + TCPM can achieve a better cosmetic effect without increasing surgery-related complications. Therefore, it deserves further application in clinical settings. 

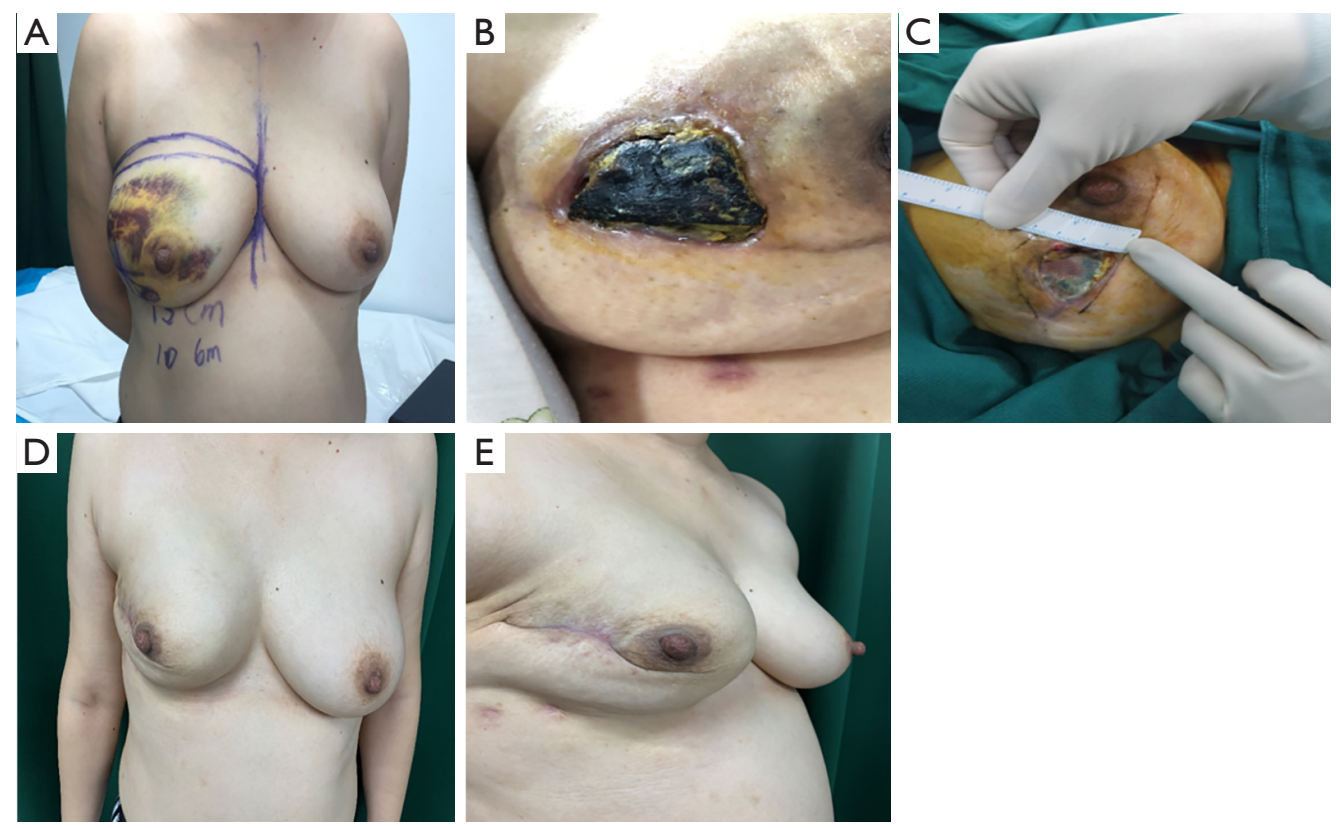

Figure 2 Repair of flap necrosis caused by postoperative hematoma in the prosthesis + TCPM group. (A) Frontal view of minimally invasive resection of the right breast at the 9 o'clock position after a diagnosis of carcinoma in situ was made; (B) local necrosis of skin flap; (C) repair of the skin flap during the reconstruction; (D) frontal view of the breast six months after reconstruction; (E) lateral view of the breast six months after reconstruction. TCPM, titanium-coated polypropylene mesh.
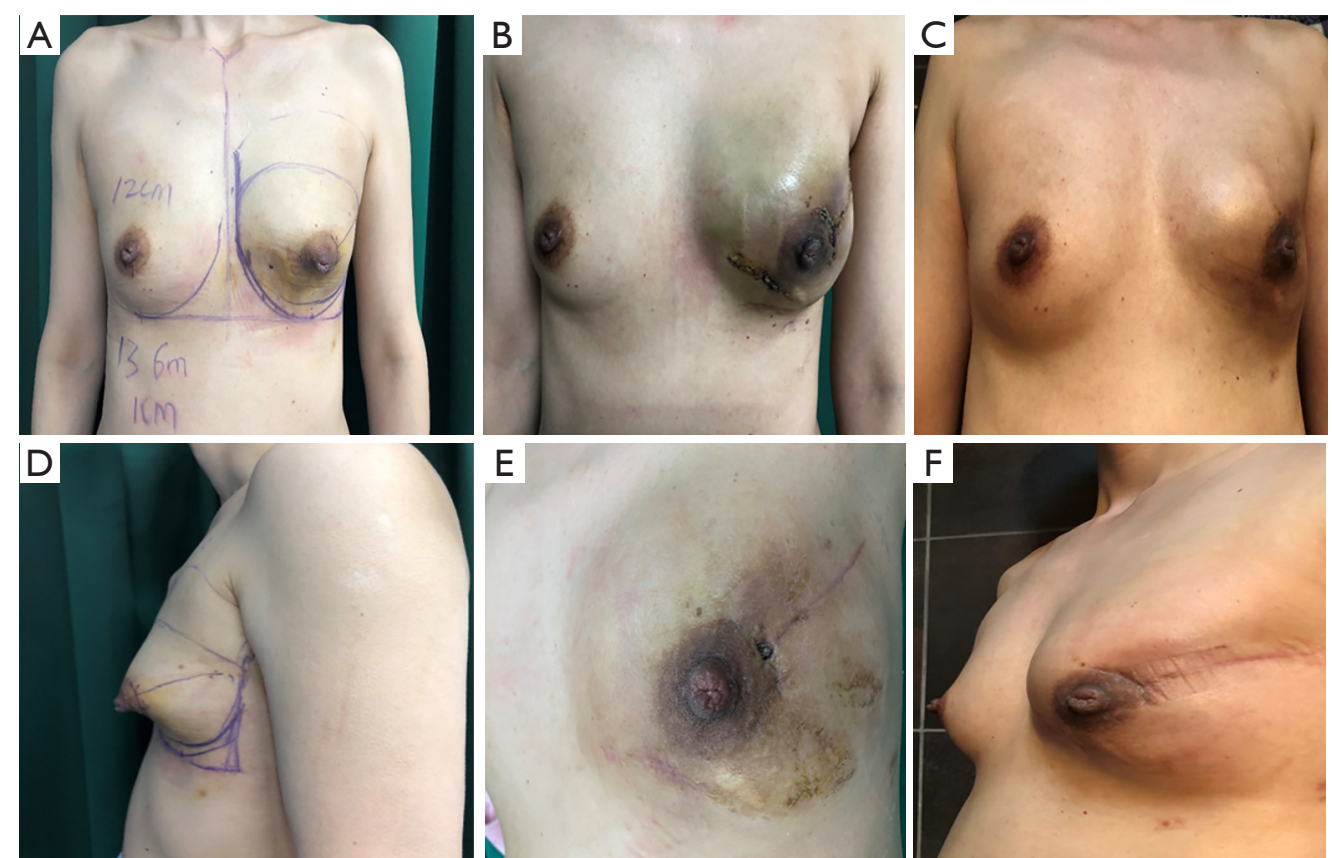

Figure 3 Hematoma appeared in a patient in the prosthesis + TCPM group, with poorly healed incision, and the wound healed after debridement and suture. (A,B) Frontal and lateral views of minimally invasive resection of the left breast at the 7 o'clock position after a diagnosis of carcinoma in situ was made; (C) hematoma appeared on the 10th postoperative day; (D) poor healing at the T-shaped junction between the periareolar incision and the radial incision on left breast; (E) frontal view of the breast 6 months after debridement and suture; (F) lateral view of the breast 6 months after debridement and suture. TCPM, titanium-coated polypropylene mesh. 

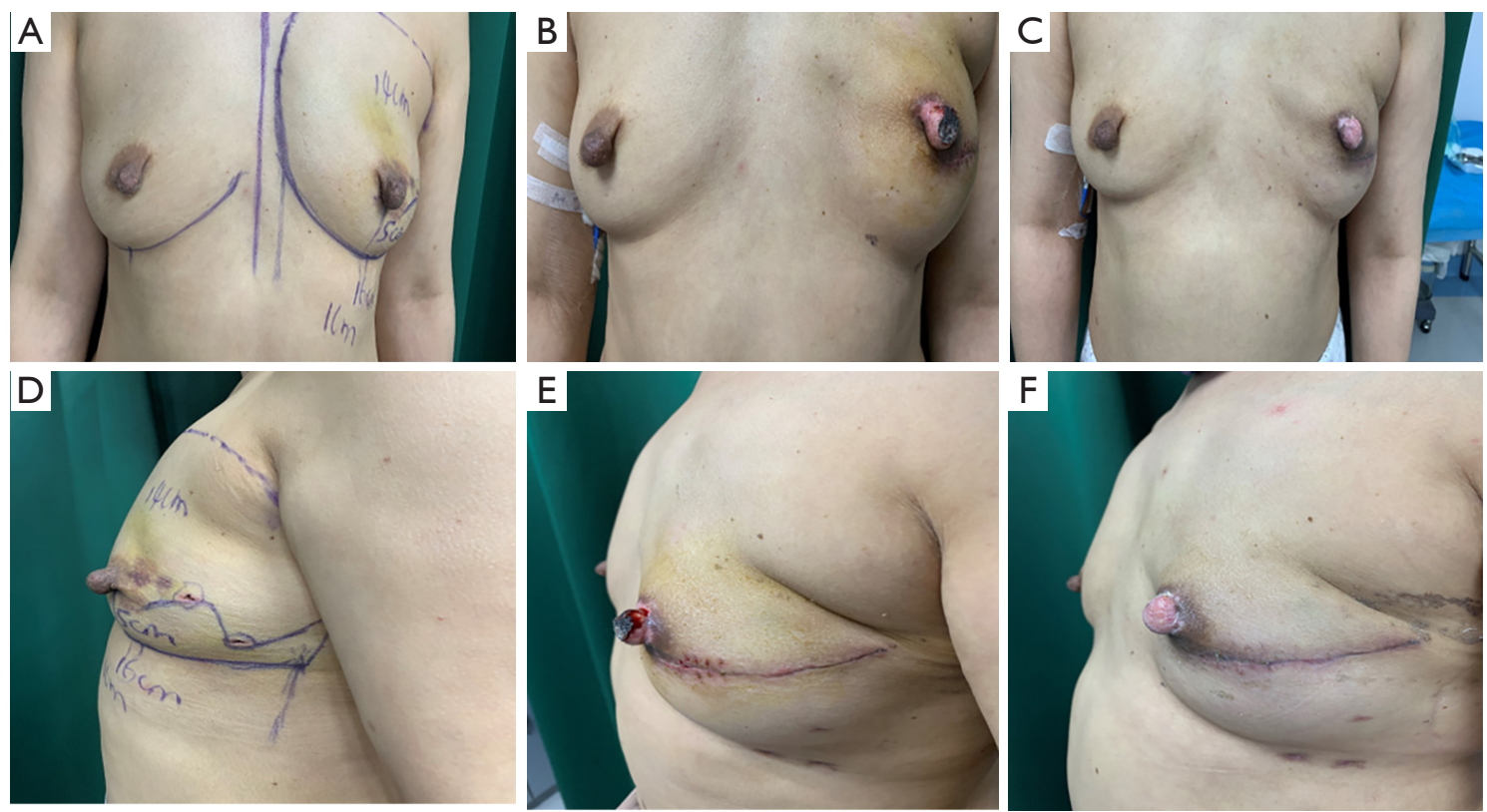

Figure 4 Reduced blood flow to the nipple in a patient in the prosthesis + TCPM group. (A,B) Frontal and lateral views of invasive ductal carcinoma diagnosed by core needle puncture; (C,D) ischemia and partial necrosis of the nipple; (E,F) frontal and lateral views of the breast 3 months after reconstruction. TCPM, titanium-coated polypropylene mesh.
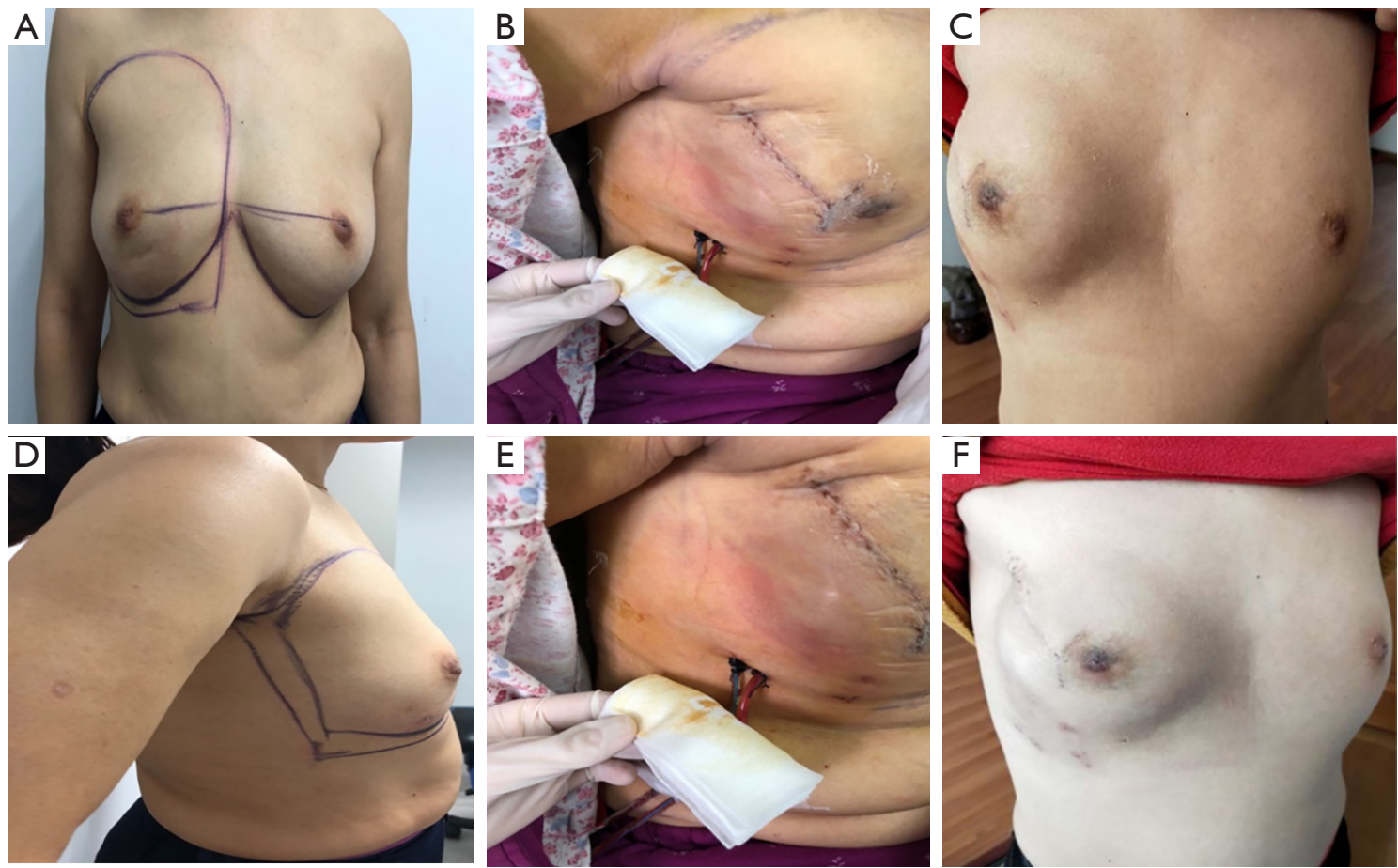

Figure 5 Postoperative infection in a patient in the simple prosthesis group. (A,B) Frontal and lateral views of minimally invasive resection of the right breast at the 6 o'clock position after a diagnosis of carcinoma in situ was made; (C,D) infection occurred 9 days after reconstruction; $(\mathrm{E}, \mathrm{F})$ frontal and lateral views of the breast 6 months after reconstruction. 

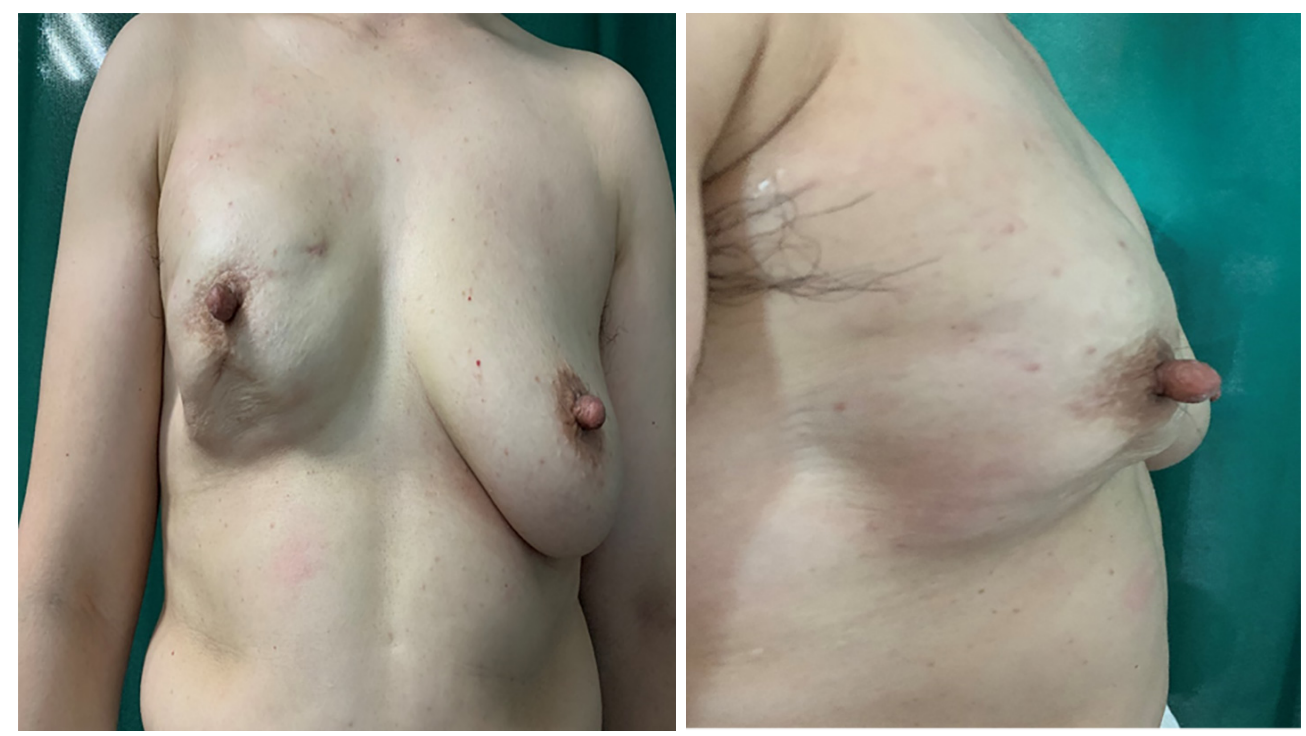

Figure 6 Capsular contracture is one patient in the simple prosthesis group.

\section{Acknowledgments}

None.

\section{Footnote}

Conflicts of Interest: The authors have no conflicts of interest to declare.

Ethical Statement: The authors are accountable for all aspects of the work in ensuring that questions related to the accuracy or integrity of any part of the work are appropriately investigated and resolved. The Medical Ethics Committee approved the study of our hospital (No. WDRY2019-K095).

\section{References}

1. Foster C, Wright D, Hill H, et al. Psychosocial implications of living 5 years or more following a cancer diagnosis: a systematic review of the research evidence. Eur J Cancer Care (Engl) 2009;18:223-47.

2. Eltahir Y, Werners LL, Dreise MM, et al. Qualityof-life outcomes between mastectomy alone and breast reconstruction: comparison of patient-reported BREAST-Q and other health-related quality-of-life measures, Plast Reconstr Surg 2013;132:201e-9e.

3. Albornoz CR, Bach PB, Pusic AL, et al. The influence of sociodemographic factors and hospital characteristics on the method of breast reconstruction, including microsurgery: a U.S. population-based study, Plast Reconstr Surg 2012;129:1071-9.

4. Cagli B, Segreto F, Santoro S, et al. A paradigm shift in U.S. breast reconstruction: part 2 . The influence of changing mastectomy patterns on reconstructive rate and method, Plast Reconstr Surg 2013;132:674e.

5. Cemal Y, Albornoz CR, Disa JJ, et al. A paradigm shift in U.S. breast reconstruction: Part 2. The influence of changing mastectomy patterns on reconstructive rate and method, Plast Reconstr Surg 2013;131:320e-6e.

6. Jagsi R, Jiang J, Momoh AO, et al. Trends and variation in use of breast reconstruction in patients with breast cancer undergoing mastectomy in the United States, J Clin Oncol 2014;32:919-26.

7. Jeevan R, Cromwell DA, Browne JP, et al. Findings of a national comparative audit of mastectomy and breast reconstruction surgery in England, J Plast Reconstr Aesthet Surg 2014;67:1333-44.

8. Saint-Cyr M, Dauwe P, Wong C, et al. Use of the serratus anterior fascia flap for expander coverage in breast reconstruction, Plast Reconstr Surg 2010;125:1057-64.

9. Isken T, Onyedi M, Izmirli H, et al. Abdominal fascial flaps for providing total implant coverage in one-stage breast reconstruction: an autologous solution. Aesthetic Plast Surg 2009;33:853-8.

10. Strock LL. Two-stage expander implant reconstruction: recent experience. Plast Reconstr Surg 2009;124:1429-36. 
11. Cordeiro PG, McCarthy CM. A single surgeon's 12year experience with tissue expander/implant breast reconstruction: part I. A prospective analysis of early complications, Plast Reconstr Surg 2006;118:825-31.

12. Spear SL, Sher SR, Al-Attar A. Focus on technique: supporting the soft-tissue envelope in breast reconstruction, Plast Reconstr Surg 2012;130:89S-94S.

13. Mioton LM, Jordan SW, Kim JY. A prospective analysis of dynamic loss of breast projection in tissue expanderimplant reconstruction, Arch Plast Surg 2015;42:309-15.

14. Breuing KH, Warren SM. Immediate bilateral breast reconstruction with implants and inferolateral AlloDerm slings, Ann Plast Surg 2005;55:232-9.

15. Scheflan M, Colwell AS. Tissue Reinforcement in Implant-based Breast Reconstruction, Plast Reconstr Surg Glob Open 2014;2:e192.

16. Colwell AS. Direct-to-implant breast reconstruction.

Cite this article as: Yao X, Guo Y, Tu Y, Yao F, Chen C, Sun $\mathrm{S}$, Zhang X. Simple prosthesis versus prosthesis plus titaniumcoated polypropylene mesh for implant-based immediate breast reconstruction after total mastectomy for breast cancer. Gland Surg 2019;8(6):773-783. doi: 10.21037/gs.2019.12.17
Gland Surg 2012;1:139-41.

17. Breuing KH, Colwell AS. Inferolateral AlloDerm hammock for implant coverage in breast reconstruction, Ann Plast Surg 2007;59:250-5.

18. Bindingnavele V, Gaon M, Ota KS, et al. Use of acellular cadaveric dermis and tissue expansion in postmastectomy breast reconstruction, J Plast Reconstr Aesthet Surg 2007;60:1214-8.

19. Harris JR, Levene MB, Svensson G, et al. Analysis of cosmetic results following primary radiation therapy for stages I and II carcinoma of the breast, Int J Radiat Oncol Biol Phys 1979;5:257-61.

20. Dieterich M, Paepke S, Zwiefel K, et al. Implantbased breast reconstruction using a titanium-coated polypropylene mesh (TiLOOP Bra): a multicenter study of 231 cases. Plast Reconstr Surg 2013;132:8e-19e. 